\title{
PLACENTUM
}

\section{SYSTEMATIC REVIEW: SENAM HAMIL UNTUK MASA KEHAMILAN DAN PERSIAPAN PERSALINAN}

\author{
A Systematic Review : Pregnancy Exercise for Pregnancy Moment and \\ Birth Preparation \\ Ulfah Hidayati \\ ${ }^{*}$ Magister Ilmu Kesehatan Masyarakat, Universitas Sebelas Maret, Jl. Ir. Sutami 36 A, Kentingan \\ Surakarta 57126 telp. (0271) 662622 \\ Email : ulfahhidayatimg13@gmail.com
}

\begin{abstract}
ABSTRAK
Latar Belakang: Ketidaknyamanan ibu hamil akan meningkat dengan bertambahnya usia kehamilan. Ibu hamil membutuhkan persiapan fisik dan psikologis untuk persalinan. Tujuan penulisan artikel ini untuk mengetahui senam hamil selama kehamilan memberikan manfaat selama kehamilan dan persiapan melahirkan

Metode: Sistematik review menggunakan database : Scopus, Pubmed, Sciene Direct, dan Emerald. Hasil pencarian yang memenuhi kreiteria adalah 8 kemudian dilakukan analisis artikel.

Hasil: Olahraga kehamilan dapat menurunkan ketidaknyamanan selama kehamilan dan mempersiapkan fisik dan psikologis kehamilan untuk melahirkan. Olahraga selama kehamilan dapat dapat dilakukan dengan senam hamil, yoga kehamilan, dan olahraga lainnya.

Kesimpulan: Senam hamil dapat menurunkan ketidaknyamanan selama kehamilan dan mempersiapkan fisik dan psikologis ibu untuk melahirkan.
\end{abstract}

Kata Kunci : Kehamilan, Olahraga, Persiapan Persalinan 


\section{ABSTRACT}

Background: Pregnant women inconveniences with increasing gestational age. Pregnant women need to prepare physical and psychological mother to give birth. This article purpose to know physical exercise during pregnancy provides benefits during pregnancy and preparation for childbirth.

Method: Systematic review with using databases: Scopus, Pubmed, Sciene Direct, and Emerald. The search results get 8 articles that match the predetermined criteria then the article analyzed.

Results: Pregnancy exercise can reduce the inconvenience during pregnancy, prepare the physical and psychological to give birth. Physical exercise during pregnancy can be done with pregnancy exercises, yoga pregnancy, and other physical exercises.

Conclusion: Pregnancy exercise helps reduce the inconvenience that raise during pregnancy and helps prepare the physical and psychological mother to give birth.

Keywords: Pregnancy, Exercises, Birth Preparation.

\section{PENDAHULUAN}

Usia kehamilan yang bertambah ibu akan mengalami beberapa perubahan, antara lain : fisik, emosional, dan status sosial pada ibu $^{[1]}$.

Ketidaknyamanan muncul akibat terjadi beberapa perubahan pada ibu ha$\mathrm{mil}^{[2]}$. Ketidaknyamanan akan bertambah pada trimester ketiga, pada trimester ketiga merupakan masa janin berkembang semakin meningkat. Perubahan fisik yang terjadi pada ibu hamil merupakan adaptasi tubuh terhadap kehamilan ${ }^{[3]}$.

Presentase ketidaknyamanan yang muncul pada ibu hamil menurut Astuti bengkak pada kaki $20 \%$, kram kaki $10 \%$, sesak nafas $60 \%$, sakit kepala $20 \%$, dan sakit punggung $70 \%{ }^{[4]}$.

Menurut Janiwarty dan Pietern perubahan psikologis ibu akan berubah pada setiap trimester ${ }^{[5]}$. Menurut Pieter dan Lubis perubahan kondisi psikologis ibu terjadi akibat peningkatan hormon progesteron selama kehamilan ${ }^{[6]}$.

Studi kecemasan kehamilan yang dilakukan Heron menyebutkan 21\% ibu hamil memiliki gejala klinis kecemasan dan $64 \%$ akan berlanjut pada masa nifas $^{[7]}$.

Penelitian yang dilakukan Hidayati pada $60 \mathrm{ibu}$ hamil dengan membanding- kan ibu hamil yang mengikuti senam dan tidak mengikuti senam hamil, hasil penelitian ini membuktikan bahwa ibu hamil yang tidak mengikuti senam hamil memiliki resiko 4 kali untuk mengalami nyeri punggung ${ }^{[8]}$. Penelitian serupa juga dilakukan oleh Fitriani penelitian melibatkan 30 ibu hamil dengan hasil 22 atau 74\% ibu hamil yang mengikuti senam hamil memiliki kualitas tidur yang baik dan tidak mengalami kecemasan untuk menghadapi persalinan $^{[9]}$. dari uraian di atas penulis tertarik untuk menulis artikel dengan judul "Senam hamil untuk masa kehamilan dan persiapan persalinan.

\section{METODE PENELITIAN \\ Strategi Pencarian}

Tinjauan sistematik melalui review artikel-artikel kebidanan untuk mengidentifikasikan senam hamil sebagai persiapan ibu melahirkan. Artikel diperoleh dengan pengambilan menggunakan internet yang terhubung dalam electronic database. Electronic database yang digunakan adalah Pubmed, Sciene Direct, Scopus, dan Proquest. Pencarian artikel menggunakan kata kunci "pregnancy", "exercises", dan "birth preparation". Pembatasan artikel dilakukan dengan menggunakan artikel yang diterbitkan setelah tahun 2010. 


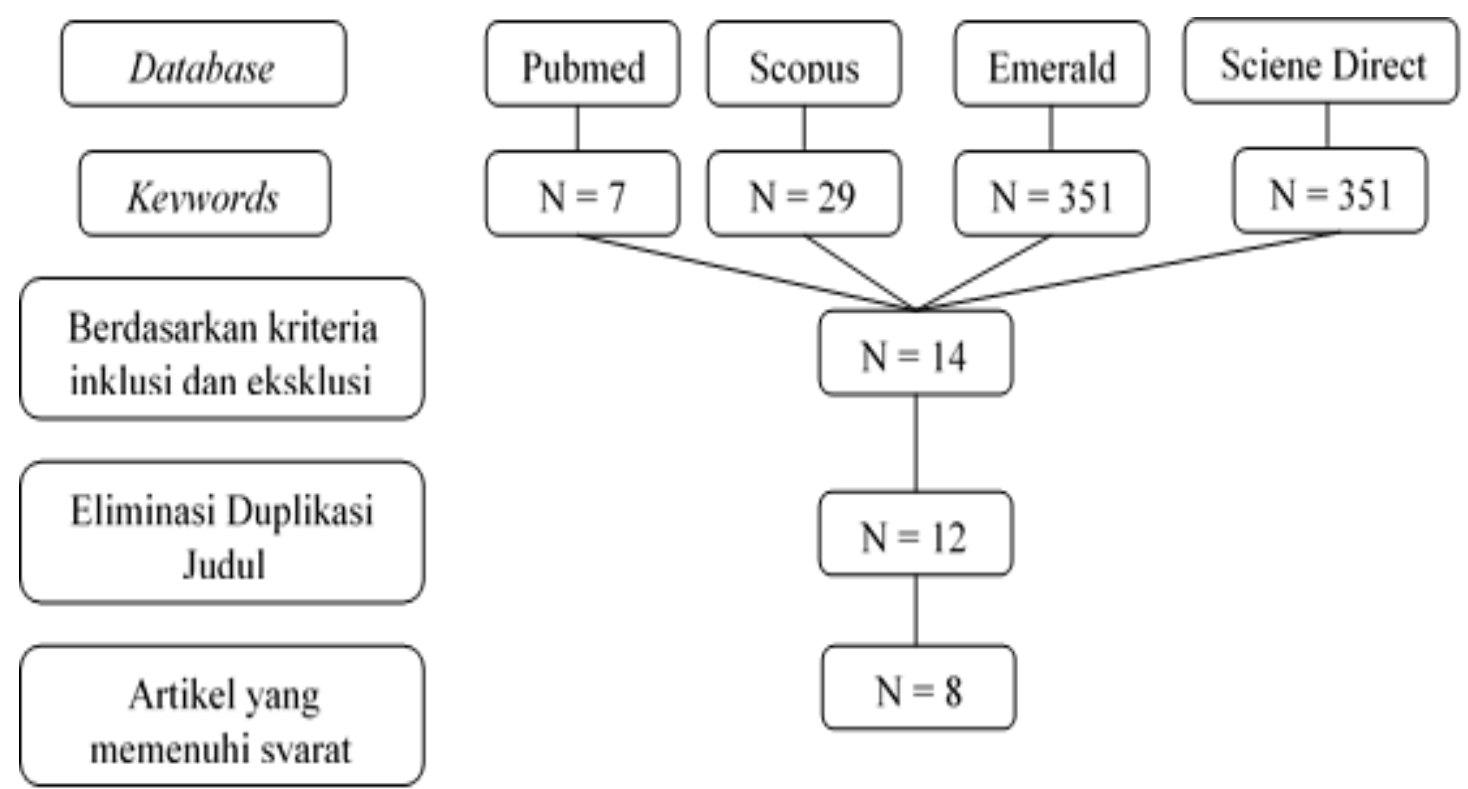

Gambar 1 : Alur Pencarian Artikel

Kriteria Inklusi dan Kriteria Eksklusi

Kriteria inklusi artikel yang digunakan : 1) Artikel yang memaparkan tentang senam hamil trimester III dan persiapan persalinan. 2) Artikel ditulis dalam Bahasa Inggris. 3) Artikel yang diterbitkan memiliki bagian yang lengkap. 4) Diterbitkan setelah tahun 2010. 5) Artikel yang tidak meneliti tentang kontraindikasi dengan senam kehamilan. 6) Artikel yang memuat perbandingan intervensi senam hamil. 7) Artikel yang memuat tentang intervensi senam hamil.

Kriteria eksklusi artikel meliputi : 1) Artikel yang terbit kurang dari tahun 2010. 2) Tidak menggunakan Bahasa Inggris. 3) Susunan artikel tidak lengkap. 4) Responden yang terlibat penelitian $<20$ ibu hamil.

\section{Alur Pencarian}

Pencarian dilakukan dengan menggunakan database Pubmed, Scopus, Sciene Direct dan Emerald menggunakan keywords : "pregnancy", "exercises", dan "birth preparation". Artikel yang muncul kemudian dipilah sehingga tidak ditemukan artikel dengan judul yang sama. Selanjutnya artikel disortir berdasarkan kriteria inklusi dan eksklusi yang telah ditentukan. Artikel yang mencantum- kan abstrak saja akan dieliminasi. Sehingga diperoleh artikel yang akan dianalisis.

\section{Ekstraksi artikel}

Artikel yang sudah didapat kemudian dilakukan ekstraksi. Ekstraksi artikel berdasarkan penulis artikel, negara, tahun terbit artikel, jumlah sampel yang digunakan, alat ukur yang digunakan, hasil penelitian yang dilakukan, dan database artikel.

\section{HASIL}

Hasil pencarian dengan menggunakan kata kunci pregnancy, exercises, dan birth preparation menggunakan elektronik $d a-$ tabase Pubmed, Scopus, Emerald, dan Sciene Direct. Hasil pencarian dengan menggunakan tiga kata kunci tersebut menghasilkan Pubmed 7 artikel, Scopus 29 artikel, Emerald 351 artikel, dan Sciene Direct 31 artikel. Kemudian dilakukan penyaringan artikel dengan kriterian inklusi dan eksklusi diperoleh 14 artikel. Pemilihan artikel selanjutnya dengan mengeliminasi duplikasi artikel dengan hasil 12 artikel. Selanjutnya dilakukan eliminasi artikel berdasarkan susunan yang lengkap yaitu sebanyak 8 artikel. 
Tabel 1. Ekstraksi Artikel

\begin{tabular}{|c|c|c|c|c|}
\hline Penulis & Negara & Tahun & $\mathrm{N}$ & Hasil \\
\hline $\begin{array}{l}\text { Miquelutti } \\
\text { MA, et.al }\end{array}$ & Brazil & 2013 & 197 & 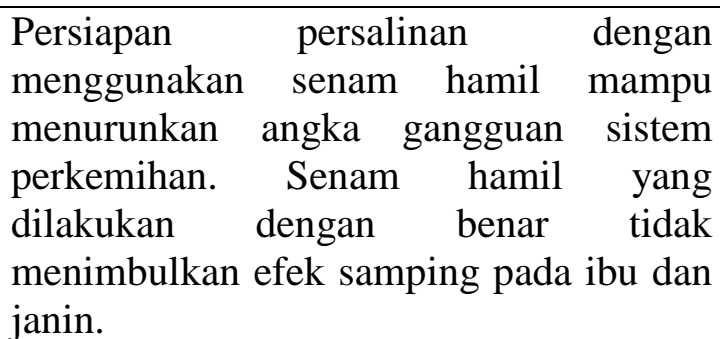 \\
\hline $\begin{array}{l}\text { Miquelutti } \\
\text { MA et.al }\end{array}$ & Brazil & 2013 & 21 & $\begin{array}{l}\text { Kelompok ibu yang mengikuti senam } \\
\text { hamil sebagai persiapan persalinan } \\
\text { mampu mengontrol rasa sakit selama } \\
\text { persalinan tanpa menggunakan bantuan } \\
\text { obat. Ibu memiliki rasa menyenangkan } \\
\text { selama menempuh persalinan. }\end{array}$ \\
\hline $\begin{array}{l}\text { Nigeria A, } \\
\text { et.al }\end{array}$ & Nigeria & 2015 & 245 & $\begin{array}{l}59,6 \% \text { ibu hamil ingin menggunakan } \\
\text { pengurangan nyeri tanpa menggunakan } \\
\text { obat. Teknik pengurangan nyeri senam } \\
\text { hamil. }\end{array}$ \\
\hline $\begin{array}{l}\text { Costa DD, } \\
\text { et.al }\end{array}$ & Perancis & 2015 & 74 & $\begin{array}{l}53,8 \% \text { ibu hamil yang tidak melakukan } \\
\text { olahraga mengalamai kenaikan berat } \\
\text { badan melebihi }\end{array}$ \\
\hline $\begin{array}{l}\text { Gallo } \\
\text { RBSG, } \\
\text { et.al }\end{array}$ & Brazil & 2017 & 80 & $\begin{array}{l}\text { Pada kelompok itervensi latihan fisik } 40 \\
\text { ibu hamil dapat menurunkan nyeri saat } \\
\text { fase kala } 1 \text { persalinan. }\end{array}$ \\
\hline $\begin{array}{l}\text { Papp EG, } \\
\text { et.al }\end{array}$ & Romania & 2014 & 160 & $\begin{array}{l}\text { Pada kelompok latiahn fisik ibu hamil } \\
\text { dihasilkan ibu memiliki kualitas hidup } \\
\text { yang baik dan merasa relaks }\end{array}$ \\
\hline $\begin{array}{l}\text { Liddle } \\
\text { SD, et.al }\end{array}$ & UK & 2015 & 5121 & $\begin{array}{l}1176 \text { ibu hamil yang mengikuti latihan } \\
\text { fisik selama } 8-12 \text { minggu dapat } \\
\text { mengurangi nyeri punggung dan nyeri } \\
\text { pelvik }\end{array}$ \\
\hline $\begin{array}{l}\text { Gau ML, } \\
\text { et.al }\end{array}$ & Taiwan & 2015 & 87 & $\begin{array}{l}\text { Studi eksperimental menunjukkan bahwa } \\
\text { implemantasi klinis dari program latihan } \\
\text { bola bisa menjadi alat tambahan yang } \\
\text { efektif untuk meningkatkan efikasi diri } \\
\text { persalinan dan mengurangi rasa sakit di } \\
\text { antara wanita dalam persalinan. }\end{array}$ \\
\hline
\end{tabular}

\section{PEMBAHASAN}

Ketidaknyamanan pada kehamilan menurut Nurdiana terjadi akibat peningkatan hormon progesteron pada saat kehamilan. Selain itu menurut Dariyo pada ibu hamil terjadi peningkatan hormon adrenalin. Kedua hormon tersebut mengakibatkan muncul keluhan ibu hamil yang mengalami ketegangan fisik. Ketegangan fisik tersebut yang menimbulkan mudah lelah dan pegal-pegal pada kaki ${ }^{[10]}$.
Sinclaer berpendapat ketidaknyamanan yang lain muncul disebabkan oleh pertumbuhan janin yang ada di uterus. Pembesaran uterus membesar kedepan. Dengan terjadinya pembesaran uterus, untuk mempertahankan keseimbangan tubuh tulang punggung condong lebih ke belakang dan otot-otot disekitarnya akan menegang. Selain itu pertumbuhan janin dalam uterus yang semakin membesar dapat mengakibatkan terjadinya perubahan tu- 
lang pada panggul. Sehingga mengakibatkan nyeri punggung dan perubahan postur tubuh yang menjadi lordosis ${ }^{[11]}$.

Perubahan psikologis ibu hamil terjadi akibat perubahan pada tubuh, tanggung jawab, menemukan hal baru dengan kehamilan yang dijalani. Perubahan kondisi tubuh pada ibu hamil mengakibatkan ibu hamil hamil tidak nyaman dan mengalami keterbatasan dalam beraktivitas ${ }^{[12]}$. Trimester III merupakan periode yang membutuhkan perhatian khusus ${ }^{[13]}$. Pada trimester III ibu hamil dihadapkan dengan persiapan persalinan. Persiapan persalinan yang kurang mengakibatkan ibu hamil akan menghadapi kecemasan dan ketakutan dalam menghadapi persalinan. Hal ini menyebabkan faktor penghambat persali$\operatorname{nan}^{[14]}$.

American College of Obstetricans and Gynecologist (ACOG) dan Hanton et.al berpendapat senam hamil merupakan gerakan kebugaran untuk melatih menguatkan otot yang berfungsi dalam persalinan. Gerakan senam hamil bertujuan untuk memacu keluarnya hormon endorfin secara alami. Hormon ini berfungsi sebagai pengurang rasa sakit selama kehamilan dan persalinan ${ }^{[15]}$.

Manfaat yang ada dalam senam hamil adalah melatih otot yang akan membantu dalam proses persalinan. Setiap gerakan senam hamil terkandung unsur teknik relaksasi. Senam hamil terdapat teknik olah pernafasan, yang dapat membantu ibu untuk menstabilkan emosi. Pada senam hamil ibu mendapatkan informasi untuk mempersiapkan diri dalam menjalani persalinan. Sehingga kecemasan, rasa takut dan rasa sakit dapat berkurang melalui relaksasi $^{[16]}$.

Miqueluitti et,al mengatakan bahwa ibu hamil yang mengikuti kelas persiapan persalinan pada usia kehamilan 30 minggu memiliki resiko inkontinesia urin yang lebih rendah (kelompok perlakuan $42.7 \%$, kelompok kontrol $62.2 \%$, RR 0.69 ; 95\% CI 0.51-0.93). Usia kehamilan 36 minggu inkontinesia urin (Kelompok perlakuan
41.2\%, kelompok kontrol 68.4\%, RR 0.6, 95\% CI 0.45-0.81) ${ }^{[17]}$.

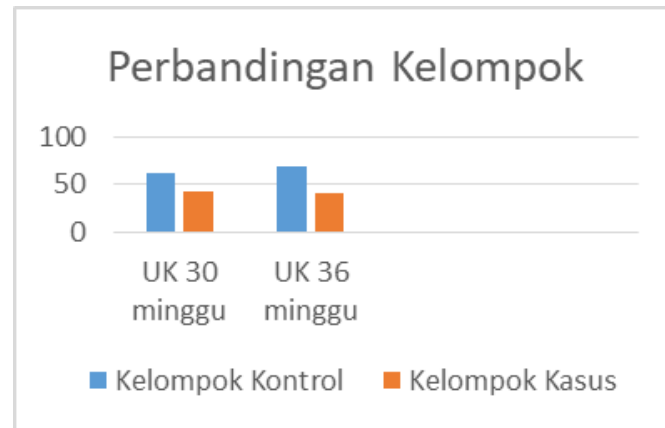

Gambar 2 : Perbandingan Kelompok Kontrol dan Kasus pada penelitian Miquelitti (2013)

Inkotinensia urin pada kehamilan terjadi karena faktor kerusakan syaraf, perubahan struktrual, dan perubahan fisiologis bagian bawah traktus urinarius. Gerakan senam hamil dengan melatih otot dasar panggul dapat meningkatkan resistensi uretra dan berdampak menambah kekuatan penutupan uretra ${ }^{[18]}$.

Penelitian pada kelompok senam hamil mampu menghadapi persalinan tanpa menggunakan obat. Ibu merasa senang karena memiliki pengalaman melahirkan yang tidak menakutkan. Teknik pengurangan nyeri yang dilakukan saat masa persalinan adalah pernafasan, bola, pijatan, air hangat, dan posisi vertikal ${ }^{[19]}$. Kelompok ibu hamil yang melakukan senam hamil 56\% memilih untuk tidak menggunakan pengurangan nyeri ${ }^{[20]}$.

Hasil penelitian yang dilakukan oleh Papp et.al menyebutkan latihan kinetoprofilaksis pada kehamilan mengalami peningkatan kapasitas relakasi ${ }^{[21]}$. Intervensi dengan latihan fisik selama kehamilan, pemijatan, dan mandi selama pembukaan 3$7 \mathrm{~cm}$ efektif mengurangi penggunaan analgesik persalinan ${ }^{[22]}$. $44 \%$ ibu hamil yang mengikuti program latihan fisik selama 8-12 minggu nyeri punggung dan nyeri pelvik berkurang ${ }^{[23]}$.

Ibu hamil yang melakukan latihan fisik dengan menggunakan senam hamil ataupun yoga dapat meningkatkan hormon endorfin. Gerakan senam hamil dan yoga terdapat relaksasi, latihan pernafasan pan- 
jang, dan meditasi. Latihan fisik tersebut dapat meningkatkan hormon endorfin dan ibu hamil akan rileks, tenang, dan dapat menghambat rangsang nyeri yang timbul pada masa kehamilan maupun persalinan ${ }^{[11]}$. Selain itu hormon enkefalin dengan latihan fisik selama kehamilan akan bertambah secara alami ${ }^{[24]}$. Hormon ini bekerja dengan hormon endorfin sebagai inhibitor transmisi nyeri ${ }^{[25]}$.

Kenaikan berat badan berlebih dapat terjadi pada masa kehamilan. Penelitian yang dilakukan Costa et.al menyebutkan dari $53.8 \%$ melebihi batas GWG (gestational weight gain) $67.6 \%$ responden tidak mengetahui kenaikan berat badan yang ideal selama kehamilan ${ }^{[26]}$.

Kenaikan berat badan pada ibu hamil yang melebihi 15-17.5 kg menyebabkan terjadi penumpukan lemak pada ibu dan janin. Selain itu kenaikan berat badan yang berlebih disebabkan oleh penimbunan cairan akibat sistem peredaran darah yang kurang lancar ${ }^{[27]}$

\section{KESIMPULAN}

Latihan fisik selama kehamilan dapat dilakukan dengan senam hamil dan yoga. Latihan fisik yang dilakukan secara berkala mampu mengeluarkan hormon endorfin dan enkefalin yang akan menghambat rangsang nyeri akibat ketidaknyamanan selama kehamilan dan persiapan persalinan. Selain itu latihan senam hamil dapat menurunkan kecemasan ibu dalam menghadapi persalinan.

\section{IMPLIKASI}

Implikasi bagi pembuat kebijakan latihan fisik pada ibu hamil dapat diterapkan pada kelas ibu hamil di seluruh wilayah kerja masing-masing di puskesmas.

\section{DAFTAR PUSTAKA}

1. Kaseuntung $\mathrm{C}$, Kundre $\mathrm{R} \quad \mathrm{B}$. Pengaruh penyuluhan kesehatan terhadap pengetahuan wanita usia subur (WUS) dalam pemilihan kontrasepsi di Desa Kalama Darat
Kecamatan Tamako Kepulauan Sangihe. ejournal Keperawatan. 2015;3.

2. Wahyuni, Layinatun N. Manfaat Senam Hamil Untuk Meningkatkan Durasi Tidur Ibu Hamil. J Kesehat Masy. 2013;8(2):113-20.

3. Pudji S, Ina H. Senam Hamil dan Ketidaknyamanan Ibu Hamil Trimester Ketiga. Midwife J. 2018;5(1):33-9.

4. Ainin N, Rosyidah T, Marharani A. Hubungan Pelaksanaan Senam Hamil dengan Ketidaknyamanan Ibu Hamil Trimester III di Bidan Praktek Mandiri Supadmi, Kunden Bulu, Sukohardjo. J Involusi Kebidanan. 2016;7(12):42.

5. Zamriati WO, Hutagaol E, Wowiling F. Faktor-faktor yang Berhubungan dengan Kecemasan Ibu Hamil menjelang Persalinan di Poli KIA Puskesmas Tuminting. J Keperawatan. 2013;1(No.1):3.

6. Melati R, Fakultas R, Uin P, Syarif $S$, Riau K. Hubungan Dukungan Sosial Suami Dengan Motivasi Dalam Menjaga Kesehatan Selama Kehamilan. J Psikol. 2012;8(2):111-8.

7. Anggit Eka R, Rina T. Pengaruh Kombinasi Senam Hamil Dengan Relaksasi Swasugesti Terhadap Kesiapan Ibu Hamil Menghadapi Persalinan. 2014;1-11.

8. Hidayati U. Pengaruh Senam Hamil terhadap Nyeri Punggung pada Ibu Hamil Trimester III di Puskesmas Baki Sukoharjo [Internet]. UNS; 2017. Available from: https://eprints.uns.ac.id/37602/

9. Fitriani R. Hubungan Senam Hamil dengan Kualitas Tidur pada Ibu Hamil Trimester III di Puskesmas Baki Sukoharjo. [Indonesia]: UNS;

10. Sulistia D. Gambaran Pengetahuan Ibu Hamil Multipara tentang Teknik Relaksasi pada Persalinan Kala I Fase Aktif di BPM Wiwik Bangunjiwo Bantul. Vol. 151, 
Repository Unjaya. 2015.

11. Mafikasari A, Kartikasari RI. Posisi Tidur dengan Kejadian Back Pain (Nyeri Punggung) Pada Ibu Hamil Trimester III. Surya. 2015;7:26-34.

12. Mintarsih W. Pendampingan Kelas Ibu Hamil Melalui Layanan Bimbingan dan Konseling untuk Mengurangi Kecemasan Proses Persalinan. 2017;12(April):277-96.

13. Mediarti D, Sulaiman S, Rosnani R, Jawiah J. Pengaruh Yoga Antenatal Terhadap Pengurangan Keluhan Ibu Hamil Trimester III. J Kedokt Kesehat Publ Ilm Fak Kedokt Univ Sriwij [Internet]. 2014;1(1):47-53. Available from: http://ejournal.unsri.ac.id/index.php /jkk/article/view/2567/0

14. Palimbo ASDA. Hubungan Pengetahuan dan Sikap Ibu Hamil dengan Kecemasan Proses Persalinan di BPM HJ. Maria Olfah Bajarmasin. Din Kesehat. 2015;6:1-5.

15. Yuniastari, Annisa Dwi P, Siti Fatimah P RDi. Analisis FaktorFaktor Yang Berhubungan Dengan Pelaksanaan Senam Hamil Di Wilayah Puskesmas Purwokerto Barat Tahun 2013. Kesehat Masy. 2014;2:283-91.

16. Larasati IP, Wibowo A. The Influence of Pregnancy Exercise to Primagravida Anxiety In The Thirth Semester For Encountering Birth Process. Biometrika dan Kependud [Internet]. 2013;1(1):2631. Available from: http://210.57.222.46/index.php/JBK /article/view/954

17. Miquelutti MA, Cecatti JG, Makuch MY. Evaluation of a birth preparation program on lumbopelvic pain, urinary incontinence, anxiety and exercise: A randomized controlled trial. BMC Pregnancy Childbirth. 2013;13.

18. Antoso BIS, Uhonni SAN, Obstetri
D. Kekuatan Otot Dasar Panggul pada Primigravida ( Penelitian Pendahuluan ). 2008;32(2).

19. Miquelutti MA, Cecatti JG, Makuch MY. Antenatal education and the birthing experience of Brazilian women: A qualitative study. BMC Pregnancy Childbirth. 2013;13.

20. Anarado A, Ali E, Nwonu E, Chinweuba A, Ogbolu Y. Knowledge and willingness of prenatal women in enugu southeastern nigeria to use in labour non-pharmacological pain reliefs. Afr Health Sci. 2015;15(2):568-75.

21. Papp EG, Szasz S, Bako AT. The Study of Pregnant Women's Kinetoprophylaxy Using Relaxation Methods. Procedia - Soc Behav Sci [Internet]. 2014;142:506-11. Available from: http://dx.doi.org/10.1016/j.sbspro.2 014.07.656

22. Gallo RBS, Santana LS, Marcolin AC, Duarte G, Quintana SM. Sequential application of nonpharmacological interventions reduces the severity of labour pain, delays use of pharmacological analgesia, and improves some obstetric outcomes: a randomised trial. J Physiother [Internet]. 2018;64(1):33-40. Available from: http://dx.doi.org/10.1016/j.jphys.20 17.11.014

23. Liddle, Pennick. Information Culture: What is Metadata? A Christmas themed exploration. Sci Am [Internet]. 2015;(9):1-36. Available from: https://blogs.scientificamerican.co $\mathrm{m}$ /information-culture/what-ismetadata-a-christmas-themedexploration/

24. Pravikasari NA, Margawati A, Mundarti. Perbedaan Senam Hamil dan Akupresur terhadap Penurunan Keluhan Nyeri Punggung Bawah 
pada Ibu Hamil Trimester III. Kesehatan. 2014;81.

25. Rahmawati P, Musviro, Fitrio D. Efektifitas Progressive Muscle Relaxation (PMR) Terhadap Penurunan Tekanan Darah pada Penderita Hipertensi. Indones J Heal Sci [Internet]. 2015;188-93. Available from: http://repository.unej.ac.id/bitstrea $\mathrm{m} / \mathrm{handle} / 123456789 / 89700 / \mathrm{F}$. Kep_Jurnal_Primasari MR_EFEKTIFITAS

PROGRESSIVE MUSCLE

RELAXATION.pdf? sequence $=1$
26. Costa D Da, Zelkowitz P, Bailey K, Cruz R, Bernard J-C, Dasgupta K, et al. Results of a Needs Assessment to Guide the Development of a Website to Enhance Emotional Wellness and Healthy Behaviors During Pregnancy. J Perinat Educ. 2015;24(4):213-24.

27. Sitanggang B, Nasution SS. FaktorFaktor Status Kesehatan pada Ibu Hamil. J Keperawatan Klin. 2012;4(1). 